is quite freely moveable over the mass. The patient feels little or no pain and generally appears to be in a condition unusually favourable in such a case, so far from the commencement of the disease. I am now using injection of doses as large as 60 minims of a 11 per cent. solution and with apparently quicker results. No symptoms of inconvenience are felt from the larger injection, but the pain caused is of somewhat longer duration. The amount of pain is not very great and this is judged because patients readily return for treatment.

Hatfield.

\section{RESEARCHES ON HIBBERTIA VOLUBILIS.} By JOHN REID, M.A., M.D., C.M. ABERD.

THE parts of the plant used in the following investigation were the fruit and the pistils which had been preserved by drying. They were obtained from Coraki and Manly Beach, two places in New South Wales. The plant was identified by the late Baron $F$. von Müller, who has also supplied the bibliography.

Extraction with acetic acid and subsequent precipitation give the alkaloid dillenine; extraction of the residue with boiling alcohol takes up the oil; while by boiling the residue with liquor potassæ a solution of potassium dillenate is obtained, from which insoluble calcium or lead dillenate may be prepared and the acid eventually isolated.

On neutralising the potassium salt with lime an acid foam may be skimmed off; it is the colouring matter which 1 propose to name "stephenic acid" after the late Rev. George Stephen of Fordyce, Banffshire. On precipitation with ammonia the acetic acid extract yields a brown-coloured neutral resin which is insoluble in ammonia, water, and chloroform, but dissolves in acids, forming a tasteless solution. Dillenine is soluble in chloroform which is used for isolating it ; acicular crystals are deposited from the solution. The dillenate of dillenine is deposited from the chloroform solution in transparent laminæ more or less perfect. The acetic acid extract contains a little dillenic acid, shown by the sherry colour produced on the addition of ammonia. In spirituous solution dillenine lessens the colouring power of tincture of guaiacum on a cat surface of potato. When heated it becomes charred and burns with an odour of burning feathers. An aqueous solution of the dillenate or acetate precipitates mercuro-potassic iodide and iodurated iodide of potassium. Given internally in doses of less than one grain of the dried substance it causes a lowering of the blood pressure; the pupil also becomes dilated and remains so for a few hours, with disturbance of the power of accommodation.

The oil is thick, almost like palm oil, and possesses the sickly odour of the flower. When boiled with caustic potash it becomes whiter but is not saponified. By keeping it becomes resinous in appearance. It is soluble in benzene, in which menstruum dillenine and dillenic acid are insoluble. When swallowed it has an irritating effect on the tongue and gullet; it probably possesses aphrodisiac qualities.

Dillenic acid is very insoluble in water and when pure is a dark resin-like powder with an acid reaction. Its solution in water does not give a precipitate with perchloride of iron, gum, or gelatin. Stronger solutions of its salts with alkali metals show the following reactions:-1. Ferrous *ulphate gives a colourless flaky precipitate in a solution which is greenish by transmitted light and dirty blar:k by reflected light; the precipitate is soluble in dilute nitric acid, the solution being light sherry coloured by reflected and transmitted light. 2. Tincture of perchloride of iron gives similar reactions, except that a light sherry colour takes the place of the green colour; some flaky deposit (di'lenic acid) appears to be undissolved in both cases on adding nitric acid. 3. Silver nitrate give; a dirty brown precipitate, : ubsiding very speedily, insoluble in dilute nitric acid but readily soluble in ammonia. 4. Silver stains on linen (recent) or on the fingers readily clear up on treatment with dillenate of

1 F. von Muller: Fragmenta Phytographiæ Australiæ, vol. vii.. p. 125 vol. xi., p. 94. Bentham: Australian Flora, vol. i., p. 19. Erseh and Gruber: Encyklopädie. Thuuberg: Transactions of the Linnæan Society, 1800. Rosenthal: Synopsis Plantarum Diaphoricarum, 1882 . soda or ammonia and free ammonia. 5. Dillenic acid dissolves sodium bicarbonate with effervescence; the salt is lighter in colour than the ammonium or potassium salts. Lead precipitates dillenic acid partially in a neutral solution or one containing a vegetable acid only and precipitates it completely in an alkaline solution. The precipitate formed with alum may be washed; it has faint astringent properties. Lime water precipitates it completely if in excess or in presence of an alkali and acetic acid redissolves the precipitate. A potassium salt gives a precipitate $(a)$ with acetic acid ; the filtrate from (a) gives a further precipitate (b) with nitric acid, and the filtrate from (b) gives with alum a precipitate $(c)$ which is much less bulky than that obtained with acetic acid. Dillenic acid seems to nullify guaiacum colouration of potato and gives no precipitate with the reagents for alkaloids. The aqueous solution of the acid or of an alkaline salt keeps well (antiseptic). It is very insoluble in rectified spirit and entirely so in chloroform. An earthworm placed in a very weak solution gave two or three convulsive tremors of its longitudinal muscles and died, presenting a flattened appearance before and after death. Possibly the substance may be valuable as a germicide. In the human subject given internally in doses of less than one grain of the dried substance it causes slight griping, nausea at the throat, and salivation, with black motions (liver stimulation). Trere is no irritant effect and the taste is if anything pleasant and sweetish. Lime water is a speedy antidote. Dillenate of zinc may be used as a. dressing.

Stephenic acid, like carminic acid, is insoluble in water. When washed it sinks as a granular precipitate and yields. with ammonia stephenate of ammonium having the colour of carminate of ammonium. The ammonium salt stains nuclei a beantiful rose colour which will not wash out like carmine and may be mounted in dammar; glycerine dissolves it so slightly that specimens stained with it may be mounted in this medium. Stephenic acid after drying is more difficult to dissolve than when it is freshly prepared. The ash of the plant consists chiefly of alumina, silica, and iron.

Southfields, S.W.

\section{Olinital 筧otes:}

\section{MEDICAL, SURGICAL, OBSTETRICAL, AND} THERAPEUTICAL.

\section{NOTE ON THE RETARDED PULSE WAVE IN AORTIC} REGURGITATION.

By Walter Broadbent, M.A., M.D. Cantab, M.R.C.P. LOÑD, M.R.C.S. ENG.

ASSISTANT PHYSTCIAN TO THE SUSSEX COUNTY HOSPITAL.

THE accompanying four tracings were taken with an instrument of precision, Mackenzie's cardiograph, attached to a Dudgeon's sphygmograph, and go to prove Sir William $H$. Broadbent's contention that the pulse in aortic regurgitation is more delayed the greater the regurgitation. The first tracing was from a normal heart and pulse to show the usual delay, the pulse being 80 to the minute. The second was from a case of slight aortic regurgitation, with very little hypertrophy and a good second sound in the neck, though the diastolic murmur in the chest was very loud. This sbowed no more delay than in the normal heart. The pulse-rate was 60 . The third was from a case of very marked aortic regurgitation with a large collapsing artery The apex beat was in the seventh space, four inches below and two inches outside the nipple; no second sound was audible in the neck. The diastolic murmur over the aortic and pulmonic areas was much less loud than in the last case. To the hand and in the tracing the pulse and heart appear to be synchronous, but the fourth tracing shows the delay between the carotid and the pulse and demonstrates that the pulse was a whole interval behind the heart, and the pulserate being 80 the delay works out at about 0.75 seconds. The delay between the apex beat and the carotid throb and between the carotid throb and the radial pulse were both appreciable to the finger. The interval between the carotid $\times 3$ 
and radial pulses was decidedly longer than with a normal heart, but that between the apex beat and the carotid was so marked that it raises the question, most difficult

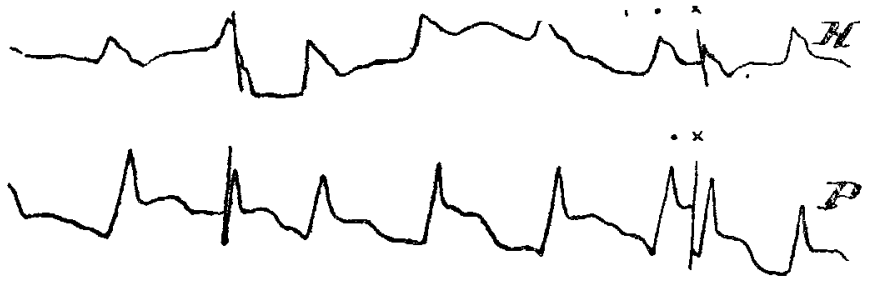

Normal.

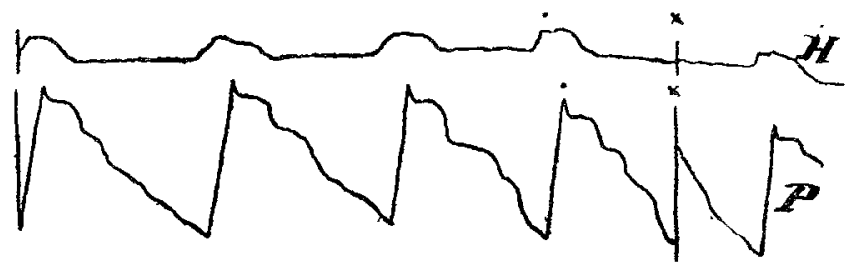

Slight aortic regurgitation.

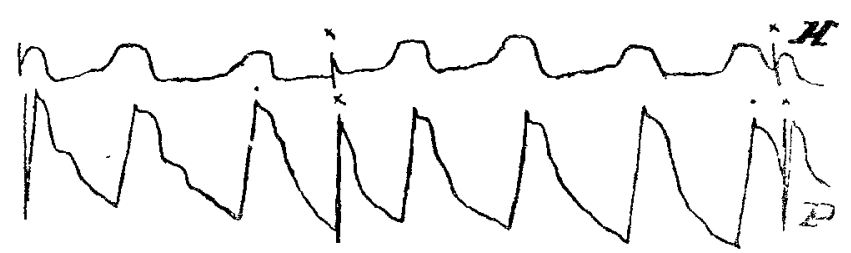

Severe aortic regurgitation.

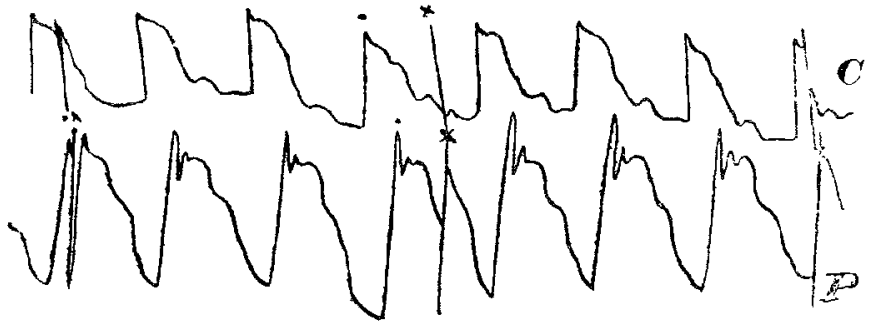

Carotid and pulse; severe aortic regurgitation.

to decide, how late in the cardiac systole does the pulse wave start from the heart when the aortic valves are practically absent?

Brighton.

\section{MICROSCOPICAL OBSERVATION OF THE GLYCOGEN REACTION.}

By Dr. Giuseppe Spezia.

IN attempting to explain the biological significance of the glycogen reaction and to account for the presence of glycogen in the white corpuscles of the blood the following experimentally ascertained facts must be kept in mind. As I have already mentioned in THE LANCET of March 7th, 1903 , p. 655 , I found that the glycogen reaction could be produced by means of subcutaneous injections of fats (olive oil or hog's lard), albuminoids (peptone), and carbohydrates (glucose). The presence of glucose and peptone in the blood is proved by the phenomena of glycosuria and peptonuria. I have found that not only has glycogen a positive chemiotaxic action but also that peptone and glucose have it. Moreover the white corpuscles drawn into the capillary glass tubes used in the experiments on chemiotaxis and filled with solution of peptone presented the glycogen reaction, whereas the white corpuscles in the blood of the same animals as were employed in the experiments did not present it. These facts prove that the leucocytes contain proteolytic, amylolytic, and lipolytic diastases which enable them to form glycogen from albuminoids, carbohydrates, and fats. It is also known that these latter substances appear in increased amounts in the blood during digestion and in many infectious diseases. Achard and Loeper have stated this with regard to glucose in pneumonia and gastro-intestinal diseases. Becquerel and Rodier have stated it with regard to fats in diseases of the respiratory organs, pneumonia, tuberculosis, and puerperal fever; the occurrence of peptonuria supplies the evidence with regard to albuminoids in pneumonia.

Bearing these facts in mind the glycogen reaction may be easily and with much probability explained as a manifestation of the process by which certain substances abnormally abundant in the blood are converted into glycogen by the action of the polynuclear leucocytes. 'The hyperlencocytosis which according to my clinical observations accompanies the glycogen reaction may be similarly explained, because these substances have a positive chemiotaxic action. The hyperleucocytosis of infectious diseases is not the first sign of resistance to pathogenic agencies exhibited by the organism. The first sign of this kind is a chemical one characterised by the appearance of the above-mertioned substances in the blood. Hyperleucocytosis is therefore based upon chemical facts.

The glycogen reaction is of practical value from a clinical point of view, for the tests which give it are easily and quickly applied and when the reaction is obtained it points to the existence of hyperleucocytosis. In the contrary event, however-namely, when the reaction is not obtainedI hardly think that the present state of knowledge would justify the inference that there is no hyperleucocytosis.

Turin.

\section{ABDOMINAL PAIN AS A SYMPTOM IN ACUTE LOBAR} PNEUMONTA.

By J. RaEside SMith, L.R.C.P. \& S. Edin., L. F.P.S. GLASG.,

LATE HOUSE PHYSICIAN AND HOUSE SURGEON AT THE INGHAM INFIRMARY AND WESTOE DISPENSARY, SOUTH SHIEIDS.

DURING the last few months several cases of acute lobar pneumonia have come under my observation. In all of these among the initial symptoms was one which is not too strongly emphasised in our text-books-namely, acute abdo. minal pain. In each case the signs and symptoms were typical of acute lobar pneumonia. I may state that in two of these cases morphia had to be administered subcutaneously on account of the severity of the symptom.

\section{A \\ oF}

\section{HOSPITA L PRACTICE, BRITISH AND FOREIGN.}

Nulla autem est alia pro certo noscendi via, nisi quamplurimas et morborum et dissectionum historias, tum aliorum tum proprias collectas habere, et inter se comparare.-MORGAGNI De Sed. et Caus. Morb., lib. iv., Procemium.

\section{LONDON TEMPERANCE HOSPITAL.}

THREE CASES OF UNUSUAL HERNIA ; HERNIOTOMY ; RECOVERY.

(Under the care of Sir William J. Collins.)

For the notes of the cases we are indebted to Mr. J. S. Hosford, surgical registrar.

OASE 1. Richter's hernia.-A single woman, aged 48 vears, was admitted into the London Temperance Hospital on Nov. 12th, 1902, complaining that she had had a lump in the right groin for a year but that four days previous to admission the lump became larger and she had suffered from vomiting and had passed neither fæces nor flatus. Her general condition was good but there were considerable abdominal distension and tenderness and some redness over the swelling in the right groin, which was of the size of a golf ball and was dull and devoid of impulse. An enema brought no motion away. At 1.45 A.M. on the 13th Sir W. Collins under chloroform cut down on the swelling in the right groin. On opening the sac a considerable quantity of sanious but odourless fluid escaped. It was clear that a portion only of the circumference of the small intestine was external to the femoral ring but acutely strangulated. Sir W. Collins 